\title{
Effect of Substrate Temperature and Zn Additive to CdTe Thin Films on AC Mechanism and Cole-Cole Diagram
}

\author{
Dr. Radhyah Mahdi Shaker Jarrah \\ University of Kufa/ Faculty of Science/ Department of Physics \\ Email: rathyah[at]yahoo.com
}

\begin{abstract}
Thin Films of pure and Zn doped CdTe have been prepared by the thermal evaporation method onto glass substrates at 500 nm film thickness. Real $\left(\varepsilon_{1}\right)$ and imaginary $\left(\varepsilon_{2}\right)$ part of dielectric constant, ac conductivity $\left(\sigma_{a c}\right)$ and cole - cole diagram of thin films for $Z n$ ratios $(00,0.02,0.04,0.06$ and0.08) have been studied in different substrate temperature as a function of the frequency range $\left(10^{2} \mathrm{~Hz}-10^{6} \mathrm{~Hz}\right)$. The results indicated that the dielectric constant increases with the increase of Zn concentration, but it decreases with the increase of frequency. The mechanism of Ac conductivity matches with the correlated barrier hoping model. From cole-cole diagram, the polarization and the relaxation time increase with the increase $\mathrm{Zn}$ concentration.
\end{abstract}

Keywords: Thin Films, Thermal Evaporation, Cole-Cole diagram, Polarization, dielectric constant.

\section{Introduction}

Over the last decades, wide band gap II-VI semiconductor thin films have attracted considerable attention from the research community because of their wide use in the fabrication of opto-electronic devices such as blue laser diodes (LDS), light-emitting diodes(LED) operating in the blue or ultraviolet spectral range ${ }^{[1-5]}$. The use of these materials is attractive because of their direct gap, low cost and also because efficient hetro-structures can be made in the polycrystalline form, with much interest shown in CdZnTe material ${ }^{[5-7]}$.

Thin film techniques are one of the most recent fullfledged technologies that greatly contribute to developing the study of semiconductors by providing a clear picture of their physical and chemical properties.

Thin films of these semiconductors were commonly grown using the conventional methods like, Chemical Vapor Deposition (CVD), Using this growth method, films can be controlled, and quality can be improved ${ }^{[8,9]}$.

Researchers have found that the electrical properties strongly depend on the $\mathrm{Zn}$ concentration and substrate temperature of $\mathrm{Cd}_{1-}{ }_{\mathrm{x}} \mathrm{Zn}_{\mathrm{x}}$ Te films so in this paper, we introduce the effect of these parameters on the structural and electrical properties of $\mathrm{Zn}_{\mathrm{x}} \mathrm{Cd}_{1-\mathrm{x}} \mathrm{Te}$ films.

\section{Theory}

From X-ray diffraction we can find the crystal plane separation (d) from Bragg's equation: ${ }^{[10]}$

$$
2 \mathrm{~d} \sin \theta=\mathrm{n} \lambda
$$

The lattice constant (a) is estimated from the equation: ${ }^{[10]}$

$$
\mathrm{a}=\mathrm{d}\left(\mathrm{h}^{2}+\mathrm{k}^{2}+\mathrm{l}^{2}\right)
$$

The average grain size dimension (D) can be evaluated from diffraction line broadening using the Scherrer's formula: ${ }^{[10]}$

$$
\mathrm{D}=0.9 \lambda / \mathrm{B} \cos \theta
$$

where $\mathrm{D}$ is the mean particle size, $\theta$ is the Bragg diffraction angle and $\mathrm{B}$ is the full width at half maximum (FWHM) of the diffraction peak.

\section{A.C. Conductivity:}

The nature of the conduction mechanism in a material can be obtained from ac conductivity $\sigma(\omega)$ versus angular frequency $(\omega)$. The electrical conductivity is measured as a function of the frequency $(\omega)$ of an alternating electric field. The frequency range in the measurements extends from $100 \mathrm{~Hz}$ to $1 \mathrm{MHz}$. The ac conductivity $\sigma(\omega)$ can be represented by the empirical formula ${ }^{[6]}$ :

$$
\sigma(\omega)=\mathrm{A} \omega^{s}
$$

Where (A) is a constant which depends on temperature, $(\omega)$ is the angular frequency and the exponent (s) is less than or equal to unity, which can be represented as ${ }^{[6]}$ :

$$
\mathrm{S}=\frac{d\left(\ln \sigma_{a, c}(\omega)\right)}{d(\ln \omega)}
$$

The total conductivity of all semiconductors $\sigma_{\text {tot }}(\omega)$ can be written as ${ }^{[6]}$ :

$$
\sigma_{\text {tot }}(\omega)=\sigma_{a_{a c}}(\omega)+\sigma_{d \cdot c}(\omega)
$$

Where $\sigma_{d . c}(\omega)$ is the d.c conductivity, then:

$$
\sigma_{\text {tot }}(\omega)=\mathrm{A} \omega^{s}+\sigma_{d \cdot c}(\omega)
$$




\section{International Journal of Science and Research (IJSR) \\ ISSN (Online): 2319-7064 \\ Index Copernicus Value (2013): 6.14 | Impact Factor (2015): 6.391}

The real $\varepsilon_{1}$ and imaginary part $\varepsilon_{2}$ of dielectric constant can be calculated from the measurements of capacitance and resistance under the presence of alternating electric field as:

$$
\varepsilon_{1}=\left(\left(\mathrm{Cd} / \varepsilon_{0} \omega\right)\right.
$$

Where, C: Capacitance, $\varepsilon_{0}$ : Permittivity of free space $=8.854 \times 10^{-12}(\mathrm{~F} / \mathrm{m})$. Where $\mathrm{d}, \mathrm{C}, \varepsilon_{0}$, and $\omega$ are film thickness, capacitance, vacuum permittivity, and angular frequency.

$$
\varepsilon_{2}=\frac{\mathrm{d}}{\omega_{0} \mathrm{RA}}=\frac{\sigma_{\mathrm{a}, \mathrm{c}}}{\omega \varepsilon_{0}}
$$

\section{Experimental Procedure}

This part deals with the methods used in the fabrication of CdZnTe alloy and thin films and various measurements which were employed for various investigations.

Two kinds of alloys ( $\mathrm{ZnTe}$ and $\mathrm{Cd}_{1-\mathrm{x}} \quad \mathrm{Zn}_{\mathrm{x}} \mathrm{Te}$ ) were prepared. In all systems a stoichiometric compound formed only when equal atomic proportions of the initial compounds with the aid of the phase diagram of $\mathrm{CdTe}$ and $\mathrm{ZnTe}$, which have provided good information about the temperature and composition. The maximum melting points of CdTe and ZnTe were approximately $1365 \mathrm{~K}$ and $1511 \mathrm{~K}$ respectively.

Appropriate atomic weights of $\mathrm{Zn}$ and $\mathrm{Te}$ with high purity $99.999 \%$ for ZnTe alloy, and appropriate atomic percentages of high purity CdTe with the resultant of $\mathrm{ZnTe}$ alloy to prepare the $\mathrm{Cd}_{1-\mathrm{x}} \mathrm{Zn}_{\mathrm{x}} \mathrm{Te}$ alloys. all weights of the elements and compounds have been weighted and then put in a clean and dry quartz ampoules ( $\mathrm{Zn}$ with $\mathrm{Te}$ ) to get $\mathrm{ZnTe}$ alloy and (CdTe with $\mathrm{ZnTe})$ to get $\mathrm{Cd}_{1-\mathrm{x}} \mathrm{Zn}_{\mathrm{x}} \mathrm{Te}$ alloy.

The constituent were mixed together and then sealed under vacuum of $10^{-3}$ Torr. Then the sealed ampules were placed in a programmable furnace type. The temperature of the furnace was raised gradually to $1373 \mathrm{~K}$ and left at this temperature for 6 hours. Then the employees were cooled down in the furnace and were broken to bring out the alloy. The last step was made the alloys into a fine powder to use for evaporation.

\subsection{Preparation of Thin Films}

Thin films of $\mathrm{Cd}_{1-\mathrm{x}} \mathrm{Zn}_{\mathrm{x}}$ Te with $(0 \leq \mathrm{x} \leq 0.08)$, were grown on cleaning glass substrates by thermal evaporation technique.
The evaporation of $\mathrm{Cd}_{1-\mathrm{x}} \mathrm{Zn}_{\mathrm{x}}$ Te thin films was done by using a vacuum system.

The vacuum can reach $\left(10^{-2}-10^{-3}\right)$ Torr. The second stage completed with operating the diffusion pump, which produced very low pressure down to $\left(10^{-6}\right)$ Torr. The glass substrate maintained at ambient temperature $(303,373$, 423) $\mathrm{K}$ during the deposition.

\subsection{Measurements}

The structures of the films were characterized by X-ray diffraction (XRD) with $\mathrm{Cu} \mathrm{K} \alpha$ radiation $\lambda=0.15406 \mathrm{~nm}$. From the peaks position and the integral width at half maximum of the respective peak, the grain sizes of prepared $\mathrm{Zn}_{\mathrm{x}} \mathrm{Cd}_{1-\mathrm{x}} \mathrm{S}$ films were calculated;

The evaporated $\mathrm{Al} / \mathrm{Cd}_{1-\mathrm{x}} \mathrm{Zn}_{\mathrm{x}} \mathrm{Te} / \mathrm{Al}$ thin films were deposited on a glass substrate at different substrate temperature $(303,373,423)$ K. A.C. Conductivity investigated using a multi frequency RLC meters model $\mathrm{HP}-\mathrm{R}_{2} \mathrm{C}(4274 \mathrm{~A}$ and $4275 \mathrm{~A})$ in the frequency range $\left(10^{2}-\right.$ $\left.10^{6}\right) \mathrm{Hz}$. To avoid any distortion and non-linear signal we must keep the amplitude of A.C signal as low as 0.08 Volt.

\section{Results and Discussion}

\subsection{Structure}

Figure (1) Shows the XRD of $\mathrm{Cd}_{1-\mathrm{x}} \mathrm{Zn}_{\mathrm{x}}$ Te thin films with $(0 \leq x \leq 0.08)$, at different substrate temperatures $(303,373$, 423) K.

The crystalline size and degree of preferential orientation were found to increase with the increase of $\mathrm{Zn}$ Concentration (x) and with substrate temperatures Ts as shown in table (1). As observed from these figure there is a strong and sharp peak at (111) reflection indicating that all films present a perfect texture along the (111) plane axis.

Also, from these figures, we can observe that there was a shift of the main Bragg's peak (111) to larger angle, indicated the changes in the lattice parameter, due to the smallness of $(\mathrm{Zn})$ content of these films and the shifting were increased with increasing of $(\mathrm{x})$, which means formation of $\mathrm{Cd}_{1-\mathrm{x}} \mathrm{Zn}_{\mathrm{x}} \mathrm{Te}$ films and this increases may be attributed to the improvement of crystallinity as a result of deposition at elevated temperature. This result is in a good agreement with Prabaker et al ${ }^{[14]}$. 
International Journal of Science and Research (IJSR)

ISSN (Online): 2319-7064

Index Copernicus Value (2013): 6.14 | Impact Factor (2015): 6.391
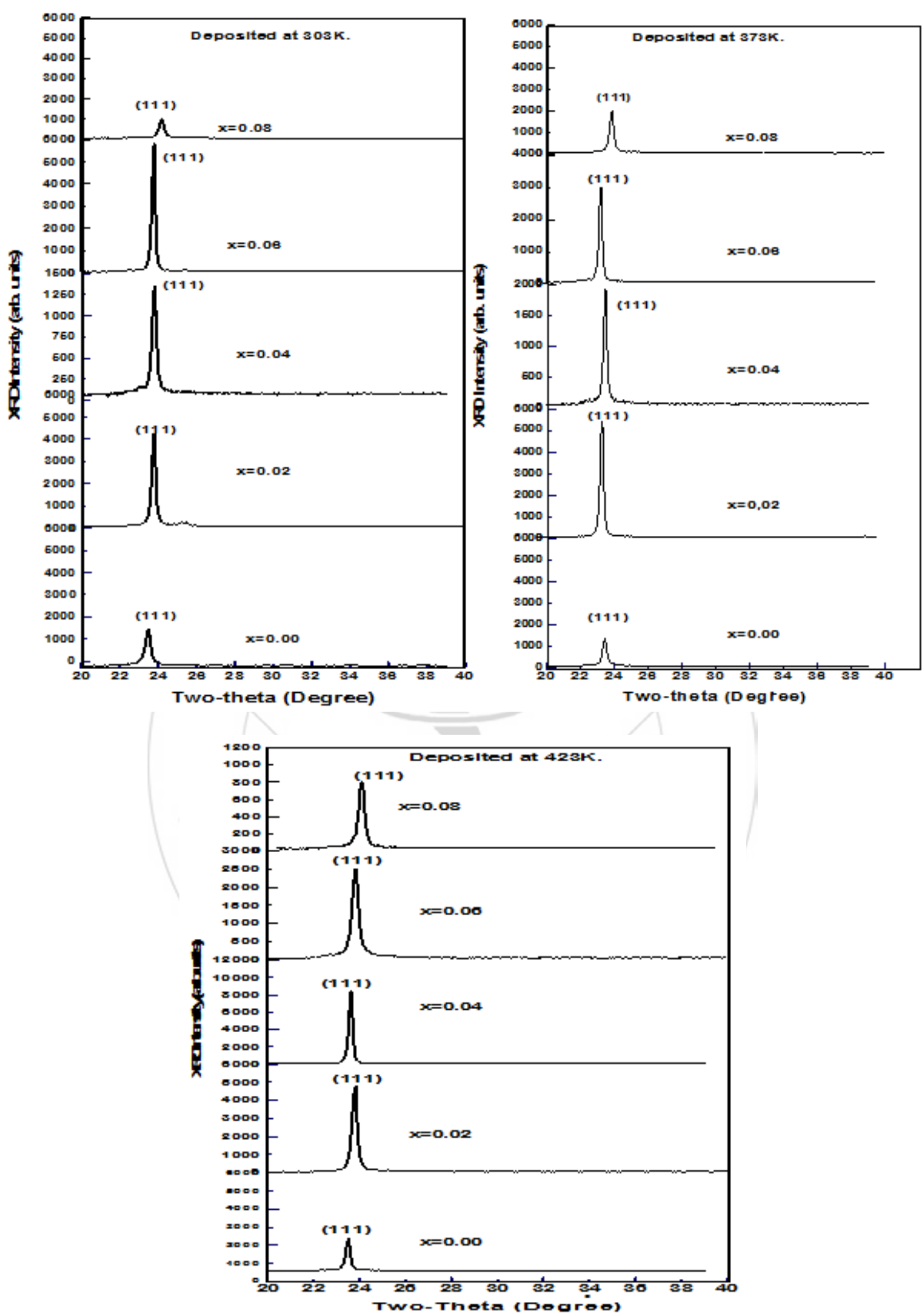

Figure 1: XRD traces of $\mathrm{Cd}_{1-\mathrm{x}} \mathrm{Zn}_{\mathrm{x}}$ Te thin films deposited at 303, 373 and $423 \mathrm{~K}$.

Volume 5 Issue 5, May 2016

www.ijsr.net 


\section{International Journal of Science and Research (IJSR) \\ ISSN (Online): 2319-7064}

Index Copernicus Value (2013): 6.14 | Impact Factor (2015): 6.391

Table 1: The values of interplanar distance d, lattice parameter and crystallite size

\begin{tabular}{|c|c|c|c|c|}
\hline Ratio of $\mathrm{Zn}$ additive & $\begin{array}{c}\text { Ts } \\
(\mathrm{K})\end{array}$ & $\begin{array}{l}\mathbf{d}_{\text {Exp }} \\
(\mathbf{n m})\end{array}$ & $\begin{array}{c}\mathbf{a} \\
(\mathbf{n m})\end{array}$ & $\begin{array}{c}D \\
(\mathbf{n m})\end{array}$ \\
\hline 00 & \multirow{5}{*}{303} & 0.3761 & 0.6490 & 24.63 \\
\hline 0.02 & & 0.3745 & 0.6460 & 36.81 \\
\hline 0.04 & & 0.3730 & 0.6456 & 39.14 \\
\hline 0.06 & & 0.3729 & 0.6457 & 44.52 \\
\hline 0.08 & & 0.3720 & 0.6448 & 27.14 \\
\hline 00 & \multirow{5}{*}{373} & 0.3750 & 0.6500 & 26.92 \\
\hline 0.02 & & 0.3743 & 0.6463 & 33.30 \\
\hline 0.04 & & 0.3738 & 0.6457 & 34.88 \\
\hline 0.06 & & 0.3736 & 0.6455 & 47.24 \\
\hline 0.08 & & 0.3711 & 0.6418 & 29.41 \\
\hline 00 & \multirow{5}{*}{423} & 0.3750 & 0.6478 & 32.91 \\
\hline 0.02 & & 0.3729 & 0.6463 & 31.10 \\
\hline 0.04 & & 0.3724 & 0.6454 & 42.84 \\
\hline 0.06 & & 0.372 & 0.6439 & 26.17 \\
\hline 0.08 & & 0.3679 & 0.6372 & 27.50 \\
\hline
\end{tabular}

3.2 A.C conductivity and dielectric properties of Cd1xZnxTe thin films

The dependence of A.C conductivity on frequency is shown in Figure (2).It is clear from this figure, that A.C. Conductivity increased with the increasing of frequency. There are two linear segments in the frequency range $\left(10^{2}\right.$ $\left.-10^{3}\right) \mathrm{Hz}$ and $\left(2 \times 10^{3}-\times 10^{6} \mathrm{~Hz}\right)$ (low and high frequency range, respectively). The frequency exponent $\mathrm{s}$ can be calculated from the slop of the straight lines in figures of $\ln \sigma$, Vs. $\ln \omega$, for high ranges of frequencies.
The obtained values of A.C activation energy of different frequencies are listed in table (2)

The general values of (s) appeared to consistent with a hopping process of carriers between localized states separated by barrier with a height. So the correlated barrier height $(\mathrm{CBH})$ model is dominant mechanism ${ }^{[13]}$.The decreasing of $\mathrm{s}$ with increasing $\mathrm{Zn}$ content is due to the hopping of charge carriers over a small barrier height.

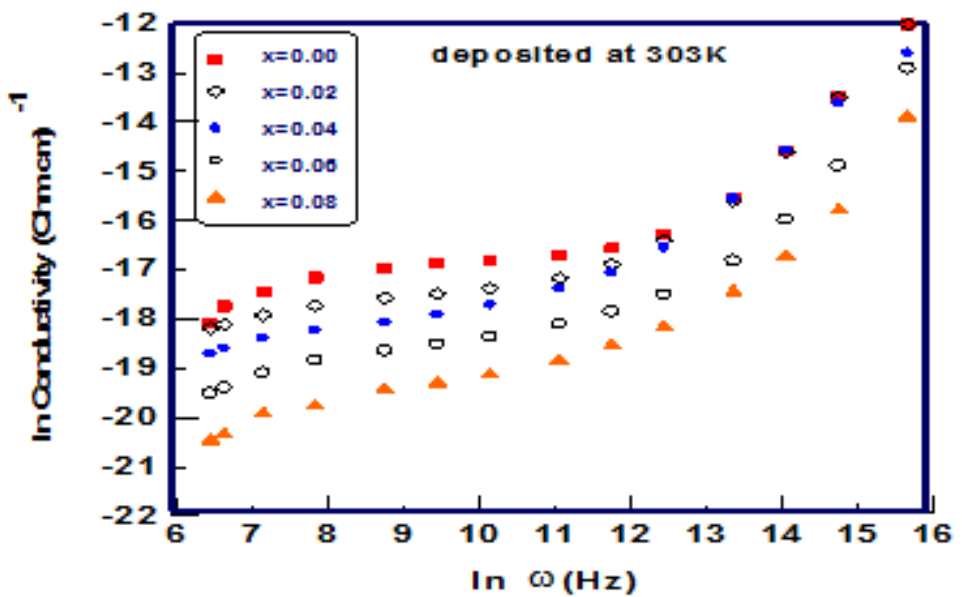

Figure 2: The variety of $\ln \mathrm{A} . \mathrm{C}$ conductivity versus frequency for $\mathrm{Cd}_{1-\mathrm{x}} \mathrm{Zn}_{\mathrm{x}} \mathrm{Te}$ thin films at different $\mathrm{Zn}$ concentration.

Table 2: A.C activation energy and exponent s of $\mathrm{Cd}_{1-\mathrm{x}} \mathrm{Zn}_{\mathrm{x}}$ Te thin films deposited at different $\mathrm{Zn}$ concentration and substrate temperature

\begin{tabular}{|c|c|c|c|c|c|c|}
\hline $\begin{array}{c}\text { Ratio of } \mathbf{Z n} \\
\text { additive }\end{array}$ & $\begin{array}{c}\mathbf{E}_{\boldsymbol{\omega} 2} \\
(\mathbf{e V})\end{array}$ & $\mathbf{( s )}$ & \multicolumn{2}{c|}{$\begin{array}{c}\mathbf{E}_{\boldsymbol{\omega} \mathbf{2}} \\
(\mathbf{e V})\end{array}$} & $\mathbf{( s )}$ & \multicolumn{2}{c|}{$\begin{array}{c}\mathbf{E}_{\boldsymbol{\omega} \mathbf{2}} \\
(\mathbf{e V})\end{array}$} & $\mathbf{( s )}$ \\
\hline & \multicolumn{2}{|c|}{$\mathrm{Ts}=303 \mathrm{~K}$} & \multicolumn{2}{|c|}{$\mathrm{Ts}=373 \mathrm{~K}$} & \multicolumn{2}{c|}{$\mathrm{Ts}=423 \mathrm{~K}$} \\
\hline 00 & 0.089 & 0.87 & 0.152 & 0.95 & 0.210 & 0.77 \\
\hline 0.02 & 0.151 & 0.85 & 0.170 & 0.87 & 0.312 & 0.82 \\
\hline 0.04 & 0.187 & 0.81 & 0.185 & 0.81 & 0.377 & 0.74 \\
\hline 0.06 & 0.212 & 0.80 & 0.184 & 0.84 & 0.320 & 0.76 \\
\hline 0.08 & 0.251 & 0.76 & 0.169 & 0.83 & 0.371 & 0.75 \\
\hline
\end{tabular}




\section{International Journal of Science and Research (IJSR) \\ ISSN (Online): 2319-7064}

Index Copernicus Value (2013): 6.14 | Impact Factor (2015): 6.391

\section{Frequency and Temperature Dependence of Dielectric Constant}

The variation of real part of dielectric constant with frequency at room temperature is shown in Figure (3). The decrease of $\varepsilon_{1}$ with frequency can be explained as follows: at low frequencies, $\varepsilon_{1}$ for polar materials is due to the contribution of multi- components of polarizability, deformational polarization and relaxation polarization. When the frequency increased, the dipoles will no longer be able to rotate sufficiently rapidly. So, their oscillations begin to lag behind those of the field. As the frequency is further increased, the dipole will be completely unable to follow the field and the orientation stopped so, $\varepsilon_{1}$ decreased at higher frequency approaching a

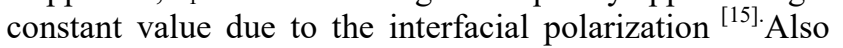
the figures show the dependence of dielectric constant $\varepsilon_{1}$ on frequency at substrate temperature (303), (373) and $(423 \mathrm{~K})$. Moreover, $\varepsilon_{1}$ increases with increase of temperature and it exhibits strange temperature dependence at higher substrate temperature and lower frequencies. The observed behavior revealed that the $\mathrm{Cd}_{1-}$ ${ }_{\mathrm{x}} \mathrm{Zn}_{\mathrm{x}} \mathrm{Te}$ exists in the form of molecular dipoles, which remain frozen at low temperature, while at high temperature the dipoles can rotate freely and an increase in $\varepsilon_{1}$ will be observed.

Figure (4) shows the variation of imaginary part of dielectric constant $\varepsilon_{2}$ with frequency. It is observed from these figure. That $\varepsilon_{2}$ was found to decrease with the increase in frequency and increase with the increase in temperature. The origins of the dielectric losses are the conduction losses, dipole losses and vibrational losses.As the temperature increase, $\sigma_{\text {a.c }}$ increases and the electrical conduction losses increase and hence increase the value of the dielectric loss $\varepsilon_{2}$.

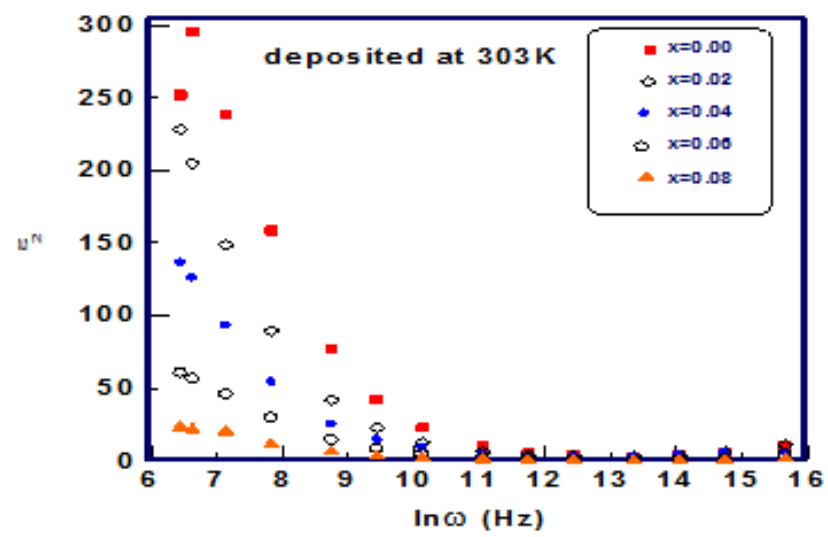

Figure 3: The variation of the dielectric constant versus in frequency for $\mathrm{Cd}_{1-\mathrm{x}} \mathrm{Zn}_{\mathrm{x}}$ Te thin films deposited at different

Zn concentration

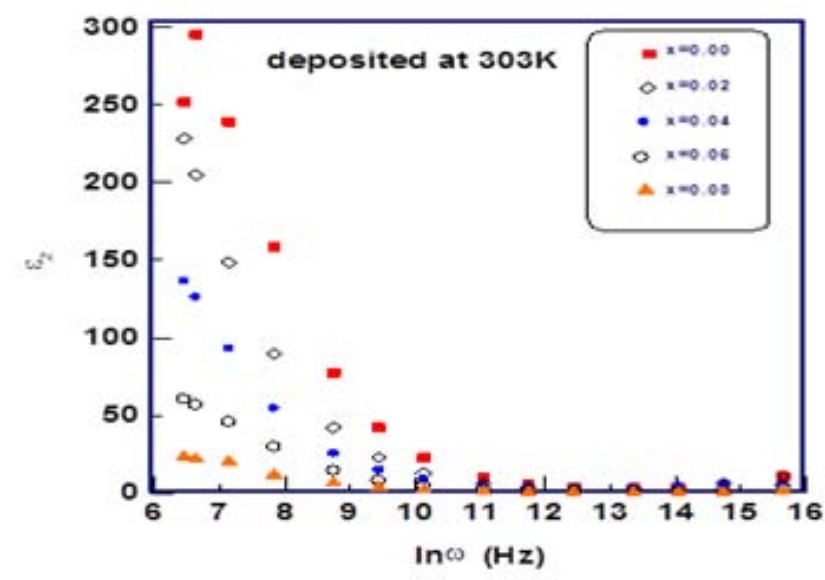

Figure 4: The variation of the dielectric loss versus $\ln$ frequency for $\mathrm{Cd}_{1-\mathrm{x}} \mathrm{Zn}_{\mathrm{x}}$ Te thin films deposited at different Zn concentration

\subsection{The Cole-Cole Diagrams}

The relation between the dielectric loss $\varepsilon_{2}(\omega)$ versus dielectric constant $\varepsilon_{1}(\omega)$ of $\mathrm{Cd}_{1-\mathrm{x}} \mathrm{Zn}_{\mathrm{x}} \mathrm{Te}$ thin films were estimated for different values of (x), is shown fig (5), illustrates a representative example for the cole-cole diagram.

A semicircle is obtained as shown in these figures. The centre of the semicircle lies below the abscissa axes by an angle $\left(\frac{\alpha \pi}{2}\right)$, where $\alpha$ is the polarizability that represents the ability of the material to move the negative ions from the positive ions. The relaxation time $(\tau)$ has been calculated for the films from cole-cole diagram by measuring $\left(\varepsilon_{s}\right)$ (the static dielectric constant) at low frequency and dielectric constant $\left(\varepsilon_{\infty}\right)$ at high frequency according to the relation $\left(\varepsilon_{s}-\varepsilon_{\infty}\right) / 2=\omega_{\max } \tau$ where $\omega_{\max }$ represents the highest frequency. Table (3) indicates the nonsystematic behavior of $\alpha$ with the increase of $\mathrm{Zn}$ ratio but $(\tau)$ increases with the increase of $\mathrm{Zn}$ ratio due to the increase of the space charges. From Figure(5) the polarizability is less than the other ratios of $\mathrm{Zn}$ due to less induced electric dipoles ${ }^{[16]}$.The increase in $\varepsilon \infty$ with temperature is due to the well-known phenomenon that the polarization increases with temperature, which was found to be valid in a wide range of materials 


\section{International Journal of Science and Research (IJSR) \\ ISSN (Online): 2319-7064}

Index Copernicus Value (2013): 6.14 | Impact Factor (2015): 6.391

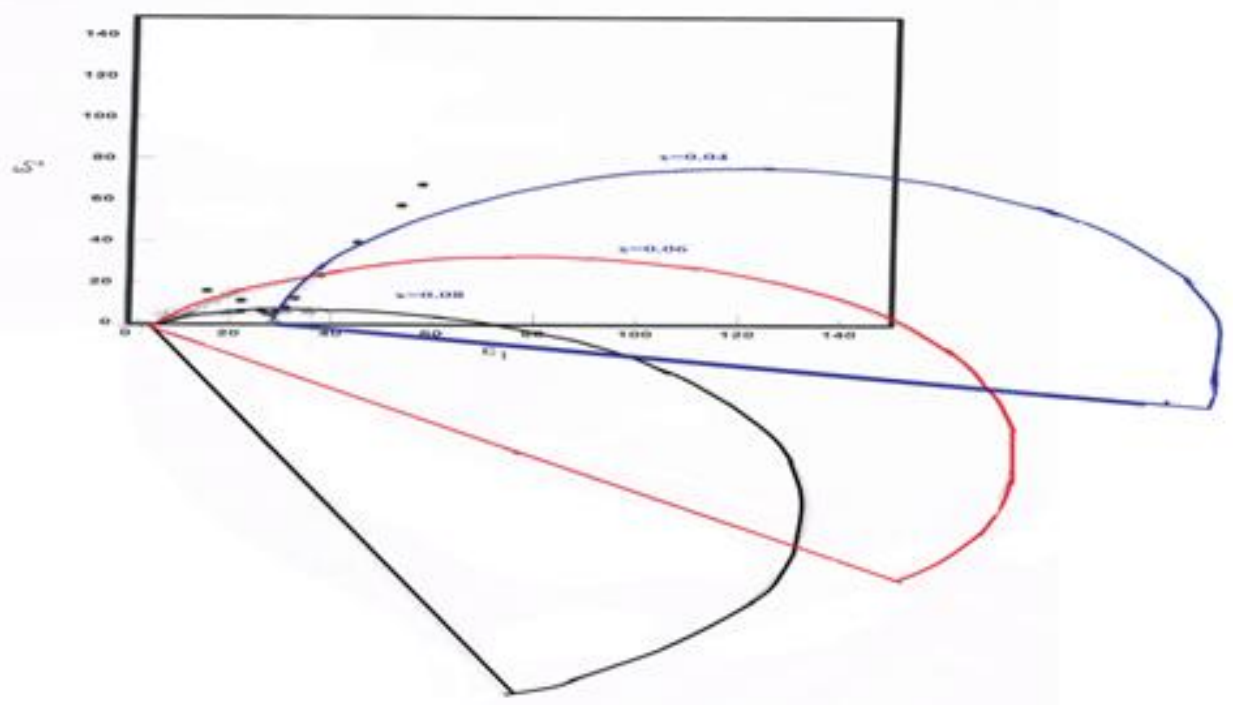

Figure 5: The Cole-Cole diagrams of $\mathrm{Cd}_{1-\mathrm{x}} \mathrm{Zn}_{\mathrm{x}} \mathrm{Te}$ thin films for variable $\mathrm{Zn}$ concentration

Table 3: values of polarization and relaxation time with Sn concentration

\section{Conclusion}

Thin Films of pure and Zn doped have been prepared by thermal evaporation method onto glass substrates at 500 $\mathrm{nm}$ film thickness. X-ray diffraction results show that the structure of $\mathrm{Cd}_{1-\mathrm{x}} \mathrm{Zn}_{\mathrm{x}} \mathrm{Te}$ films is polycrystalline with cubic structure. The grain size increased with increasing substrate temperature and decreas with the increase of $\mathrm{Zn}$ concentration. Real part of dielectric constant $\left(\varepsilon_{1}\right)$, imaginary part of dielectric loss $\left(\varepsilon_{2}\right)$, ac activation energy and cole - cole diagram of thin films for $\mathrm{Zn}$ ratio $(0 \%, 2 \%$, $4 \%, 6 \%$ and $8 \%$ ) have been studied at different substrate temperature as a function of frequency range $\left(10^{2} \mathrm{~Hz}-10^{6}\right.$ $\mathrm{Hz}$ ). The results indicated that the real part of dielectric constant increases with the increase of $\mathrm{Zn}$ concentration but decreases with the increase of frequency. The imaginary part of dielectric constant has a maximum value at $(2 \%$ and $4 \%)$ of $\mathrm{Zn}$ ratios. The mechanism of ac conductivity matches with correlated barrier hoping $(\mathrm{CBH})$ model. From cole-cole diagram, the minimum value of polarizability of $2 \%$ of $\mathrm{Zn}$ and the relaxation time increase with the increase of concentration.

\section{References}

[1] A. Alnaimi, and M. N. Al-Dileamy, " Determination of the Optical Constant of Cadmium. Stannate $\left(\mathrm{CdSnO}_{4}\right)$ Films", International J. Pure and Applied Physics, Vol.3 No 1 (2007) pp30-39.

[2] S. Oswald, and S. Baunack, " Comparison of Depth Profiling Techniques Using Ion Sputtering from the Practical Point of View" J.Thin Solid Films Vol. 425(2003)PP 9-19.
[3] J. Cheon and J. I. Zink, "Gas Phase Photochemical Synthesis of II-VI Metal Sulfide Films and in Situ Luminescence Spectroscopic Identification of Photofragments" J. 4-J. E. Ayers "Hetroepitaxy of Semiconductors, Theory, Growth and Characterization", University of Connecticut, Storrs, CT, U.S.A.by Taylor \& Francis Group, LLC, (2007).

[4] K. Kishino and I. Nomura, "Optical Device Materials for a Wide Visible Spectral Region, , Photonics Based on Wavelength Integration and Manipulation ", IPAP Books 2 (2005) pp 39-48.

[5] L. P.Deshmukh, K. M.Garadkar, and D.S.Sutrave, "Studies on Solution Grown $\mathrm{Hg}_{\mathrm{x}} \mathrm{Cd}_{1-\mathrm{x}} \mathrm{S}$ Thin Films", J. Materials Chemistry Physics, Vol.55(1998)PP.30-35.

[6] W. Faschinger, "Doping Limits and Bandgap Engineering in Wide Gap II-VI Compounds" Baker \& Taylor, United States publication, (2001) pp1-37.

[7] C. S. Induikar and S. Thiruvengadam, "An Introduction to Electrical Engineering Materials, Third Edition, S. Chand and Company LTD., Ramnagar, New Delhi, Reprinted(1990).

[8] S. Tobeňas, E. M. Larramendi, and E. Purơn, "Growth of $\mathrm{Cd}_{1-\mathrm{x}} \mathrm{Zn}_{\mathrm{x}} \mathrm{Te}$ Epitaxial Layers by Isothermal Closed Space Sublimation", J. Crystal Growth Vol.234(2002)PP311-317.

[9] N. F. Mott, E. A. Davis, "Electronic Process in NonCrystalline Materials", Second Edition, Oxford University Press (1979).

[10] M. M. El-Nahass, A. M. Farid K. E. Abd El-Rahman, and H. A. M. Ali, "AC Conductivity and Dielectric Properties of Bulk Tin Pthalcyanine Dichloride $\left(\mathrm{SnPcCl}_{2}\right)$ )", J. Physica B, Vol. 403 2008) PP. 23312337. 


\section{International Journal of Science and Research (IJSR) \\ ISSN (Online): 2319-7064}

Index Copernicus Value (2013): 6.14 | Impact Factor (2015): 6.391

[11] K. K. Srivastava, A. Kumar, O. S. Panwar, "Dielectric Relaxation Study of Chalcogenide Glasses", J. NonCrystalline Solids, Vol. 33 (1979) PP. 205-224.

[12] J. H. Park, K. H. Yoon, D. H. Kang, "Effect of PMN Addition on Dielectric Properties of PZT Thin Films Synthesized by Modified Chemical Solution Process ", J. Materials Chemistry and Physics, Vol. 79 (2003) PP. $151-153$.

[13] K. Prabakar, S. K. Narayandass, and D. Mangalaraj, "Dielectric and Electric Modulus Properties of Vacuum Evaporated $\mathrm{Cd}_{0.2} \mathrm{Zn}_{0.8}$ Te Thin Films", J. Materials Science and Engineering B Vol.98 (2003) PP 225-231.

[14]S. MahmoudU, A. Ibrahim, Physical properties of thermal coating $\mathrm{CdS}$ thin films using a modified evaporation source, Thin Solid Films 372 (2000). Pp144-148.

[15] I. Ibrahim, Density of states of CdTe thin films, AlMustansiriyah J. Sci, 22, No. 5, (2011) 284-290

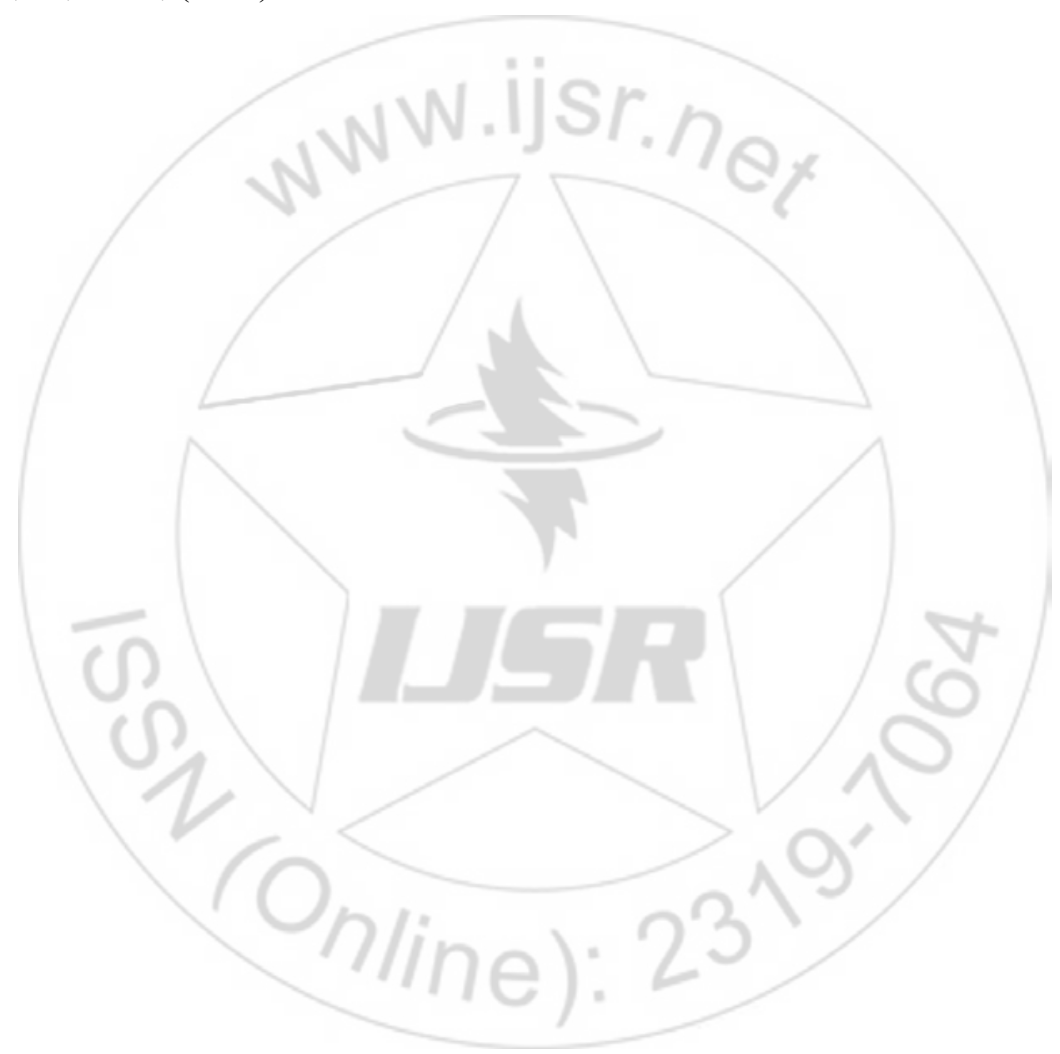

